http://www.jfas.info

\title{
DOPPLER SPECTRUM ANALYSIS OF HELICOPTER FOR AN ACTIVE SEEKER HEAD
}

\author{
S. Ahmad* and K. A. Ahmad \\ Department of Electrical and Electronic Engineering, Faculty of Engineering, National \\ Defence University of Malaysia, 57000 Kuala Lumpur, Malaysia
}

Published online: 10 September 2017

\begin{abstract}
The pulsed Doppler of a helicopter as the angle between a seeker line of sight (LOS) and the plane of rotor varied is explored. A special emphasis is placed to determine the variation of the Doppler strength and frequency from the main rotor blades. This paper also reviews some literatures related to helicopter detection. An experiment consisting a model helicopter, radar and some measuring equipment is described. The result shows that the strength of the Doppler signal increases as the angle increases. On the other hand, the Doppler frequency from the rotating blades reduces as the angle increases. The analysis of the results indicates that MMW radar is very suitable to be used as an active seeker head especially if the missile is used to attack a hovering helicopter.
\end{abstract}

Keywords: radar; active seeker; Doppler signature; helicopter; hovering.

Author Correspondence, e-mail: shahril@upnm.edu.my

doi: http://dx.doi.org/10.4314/jfas.v9i3s.10

\section{INTRODUCTION}

Helicopter Doppler signatures have been the subject of numerous theoretical and experimental studies [1-3]. Typically, the radar RCS of an attack helicopter fuselage is small and the RCS 
of the rotor blades are even smaller. When the helicopter is hovering, the RCS from the fuselage cannot be distinguished from the ground clutter and only the moving rotor blades may be visible. Detecting the blade flash by at long range by a surveillance radar is possible because the small RCS can be overcome by using relatively big antenna (aperture) and high transmitted power. However, for an active seeker head, the missile diameter limits the size of the effective aperture and the on board power supply does not allow the seeker to radiate much power. Furthermore, if a missile is launched towards an area where a helicopter is hidden, the seeker must confirm that it is about to engage a helicopter and not something else nearby. Faced with a concrete task, the author decided to experimentally explore the possibility of a seeker head being able to discriminate Doppler spectrum of a helicopter from any other targets. Work done by [4] who stated that the rotor blade can be modeled as a stiff rod of a length $\mathrm{L}$ and a physical cross section $\mathrm{S}$ which (as seen from the radar direction) can be assumed to have RCS about $0.5 \mathrm{~m}^{2}$. Therefore, if the rotor blade is positioned at an angle relative to the radar beam as shown Fig. 1, the graphical representation of a single blade echo as function of aspect angle is shown in Fig. 2.

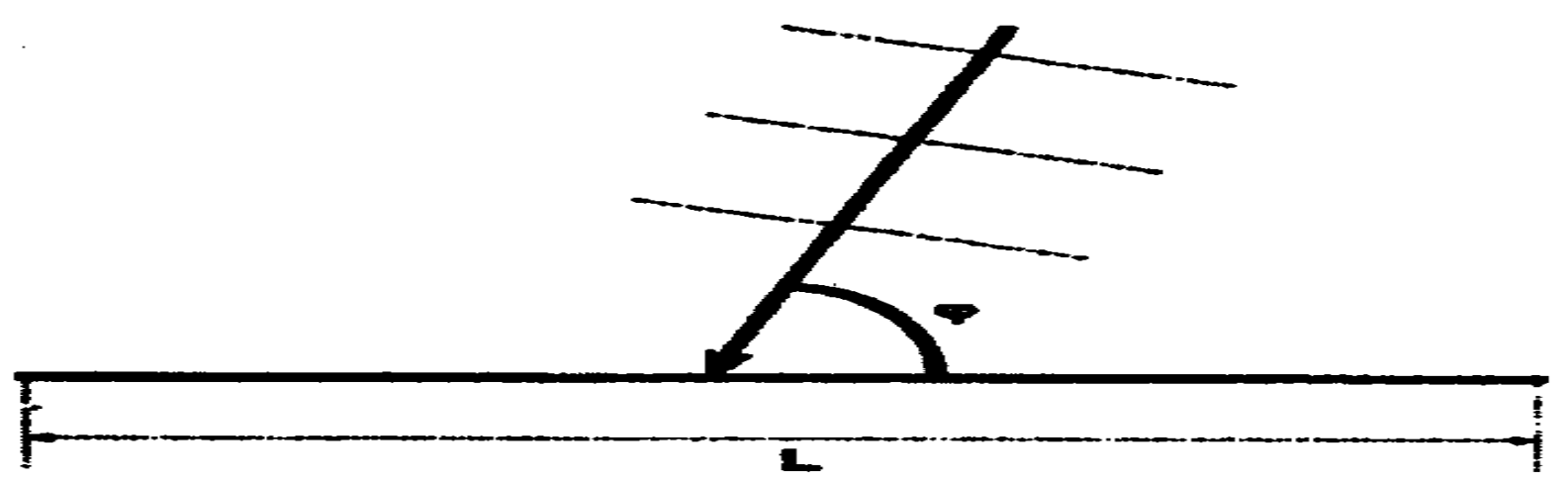

Fig.1. Geometry of a blade model

They demonstrated that the maximum amplitude drops sharply from small changes in aspect angle. Hence, the maximum rotor echo of a real helicopter presents short flashes of the blades, occurring when the blades are perpendicular to the radar beam. 


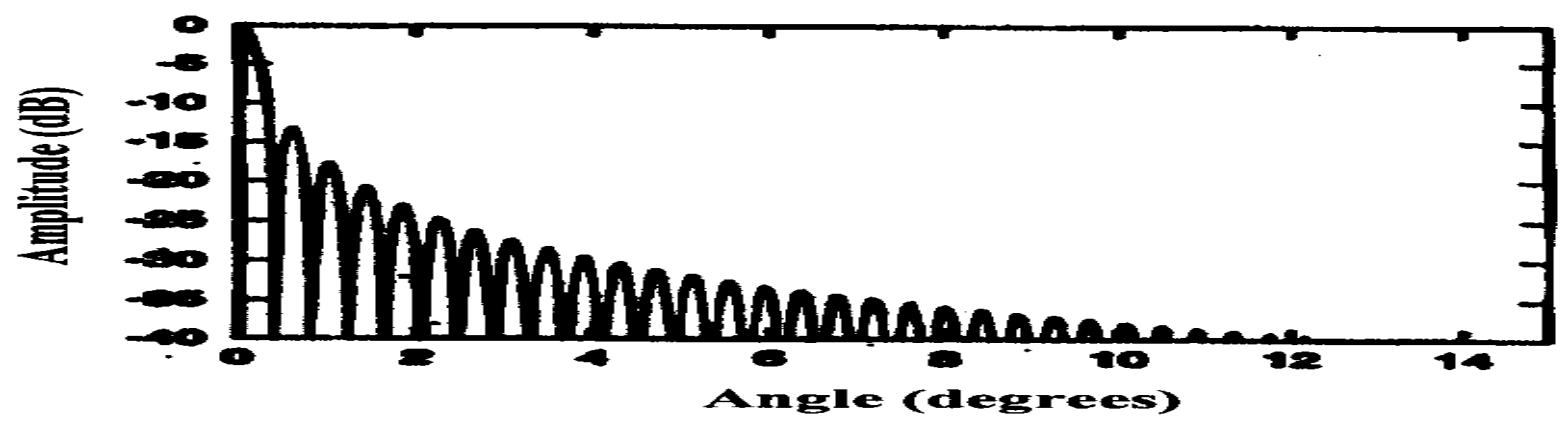

Fig.2. Amplitude of single blade echo as a function of aspect angle

They also have gathered the resulting flash durations and intervals of several helicopters as shown in Table 1. It reveals that the flash duration for any type of helicopter is practically the very close and depends only on whether the number of blades is odd or even.

Table 1. Rotor parameters of common helicopters

\begin{tabular}{cccccc}
\hline Helicopter Type & $\begin{array}{c}\text { Number } \\
\text { of Blade }\end{array}$ & $\begin{array}{c}\text { Rotation Rate } \\
\mathbf{( r p m )}\end{array}$ & $\begin{array}{c}\text { Rotor } \\
\text { Diameter (m) }\end{array}$ & $\begin{array}{c}\text { Flash } \\
\text { Interval (ms) }\end{array}$ & $\begin{array}{c}\text { Flash } \\
\text { Duration (ms) }\end{array}$ \\
\hline Bell 206B Jet Ranger & 2 & $374-394$ & 10.16 & 78 & 0.24 \\
Bell 209 Cobra & 2 & $294-324$ & 13.41 & 97 & 0.23 \\
MI-2 & 3 & 246 & 14.6 & 40 & 0.53 \\
PZL W-3 Sokol & 4 & 254 & 15.7 & 59 & 0.24 \\
MI-8 & 5 & 192 & 21.29 & 31 & 0.46 \\
\hline
\end{tabular}

From the experiment, they captured the radar echoes of MI-2 helicopter. Since the radar PRF is $4000 \mathrm{pps}$, in $1 \mathrm{~ms}$ there are 4 sampling intervals. Fig. 3 indicates that the spikes are separated by about 160 samples which corresponds to $40 \mathrm{~ms}$. Hence, the spikes represent the blade flash interval of MI-2 helicopter and it is similar to the calculated value as shown in Table 1.

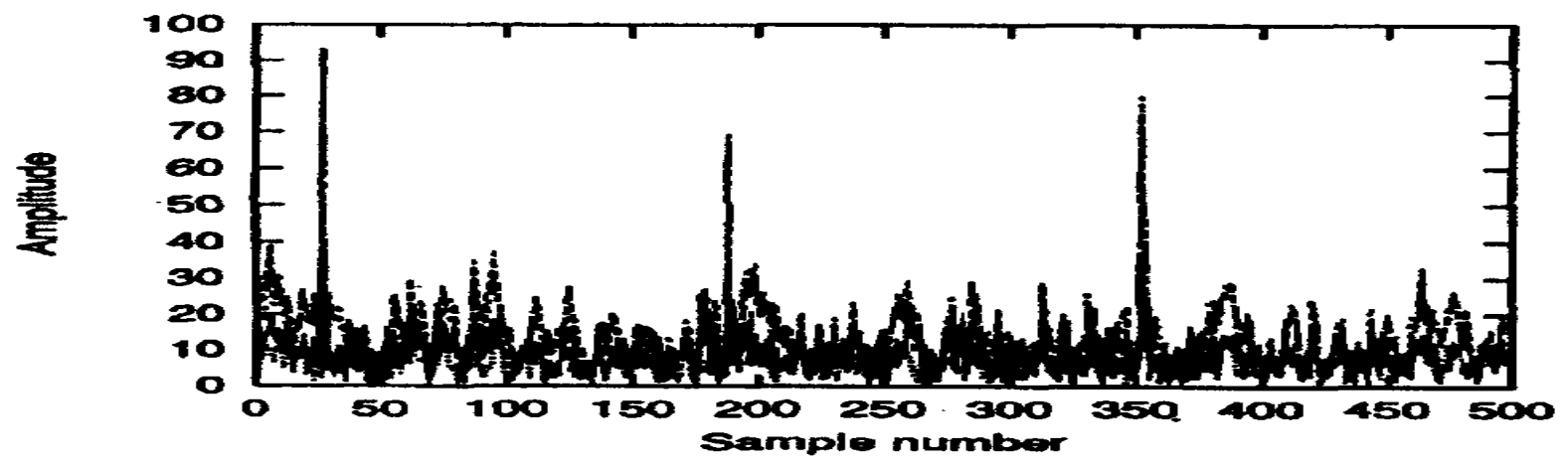

Fig.3. Main rotor blade flashes 
In [5] describes pulsed Doppler signature of a helicopter based on an experiment done by U.S Army Missile Command and Georgia Tech using an instrumented high pulsed repetition frequency X-band coherent radar and a modified Sikorsky S-55 helicopter. It had gathered the tip speed of the main and tail rotor of several helicopter as listed in Table 2. The table points out that the tip speed of the main and tail rotor does not deviate much.

Table 2. Typical helicopter tip speeds

\begin{tabular}{ccc}
\hline Type & Main Rotor Tip Speed (m/s) & Tail Rotor Tip Speed (m/s) \\
\hline AH-Huey Cobra & 227 & 225 \\
AH-Apache & 221 & 206 \\
UH-60 Black Hawk & 221 & 209 \\
CH-53 Stallion & 223 & 223 \\
MD 500E Defender & 207 & 215 \\
A 109 Agusta & 222 & 222 \\
AS 32 Super Puma & 217 & 204 \\
SA 365 Dauphin & 218 & 227 \\
\hline
\end{tabular}

Based on the results of the experiment, it describes that the radar signature of the helicopter can be classified into four components as depicted in Fig. 4. The interval between the distinct peaks (Fig. 5) in the time domain corresponds to the period of consecutive rotor blades (advancing or retreating) during maximum target area. The peaks are formed when the rotor blades are perpendicular to the line of sight.

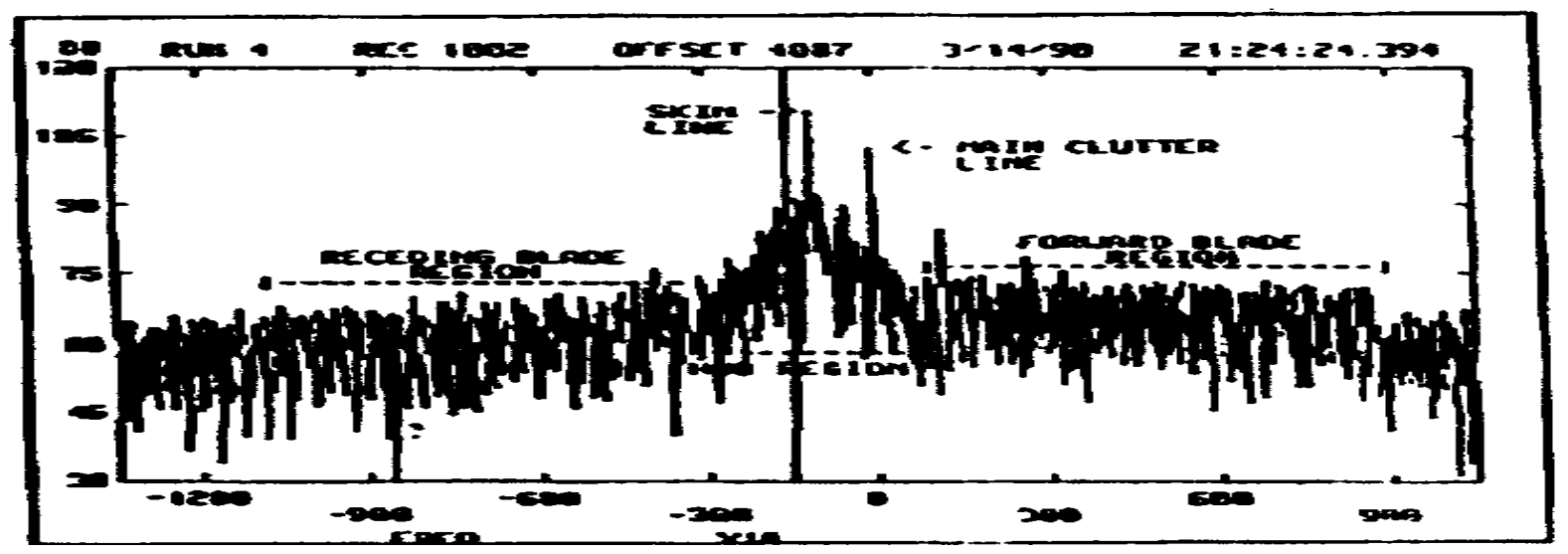

Fig.4. Helicopter Doppler signature 


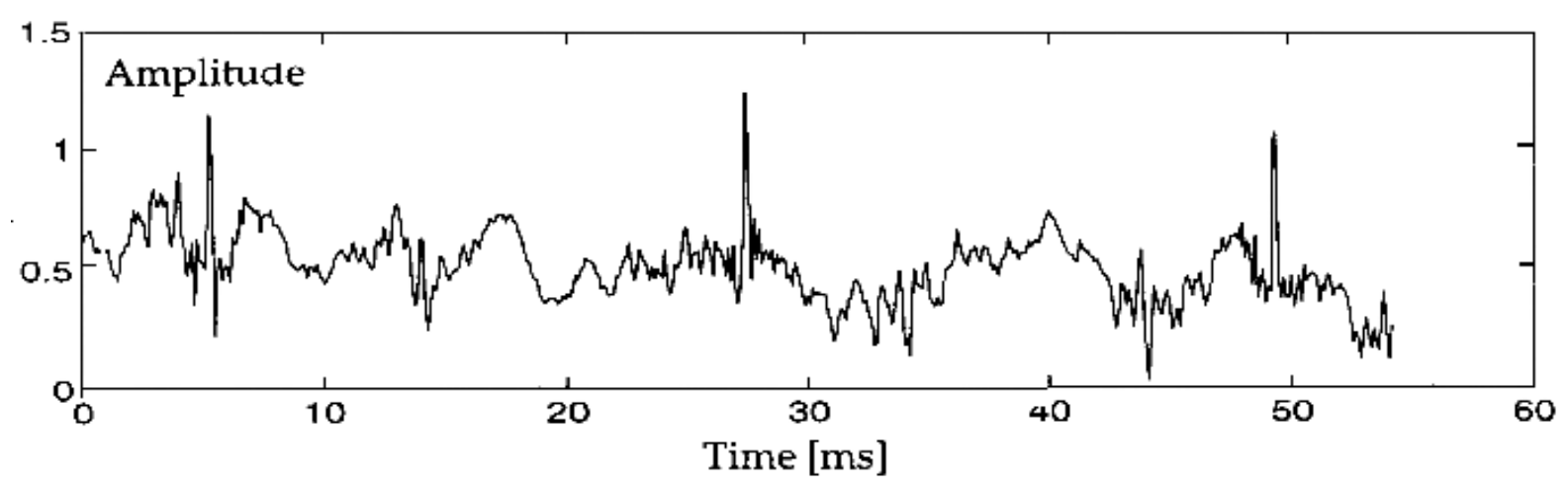

Fig.5. Helicopter Doppler signal in time domain

For helicopters with an even number of rotor blades, the backscattered signal in the frequency domain will be symmetrical since signals of approaching and receding blades will be simultaneous as shown in Fig. 6. However, if the integration time is too short, the spectrum can be asymmetric for helicopters with an odd number of blades. Approaching and receding blades will give only positive Doppler velocities or negative Doppler velocities respectively.

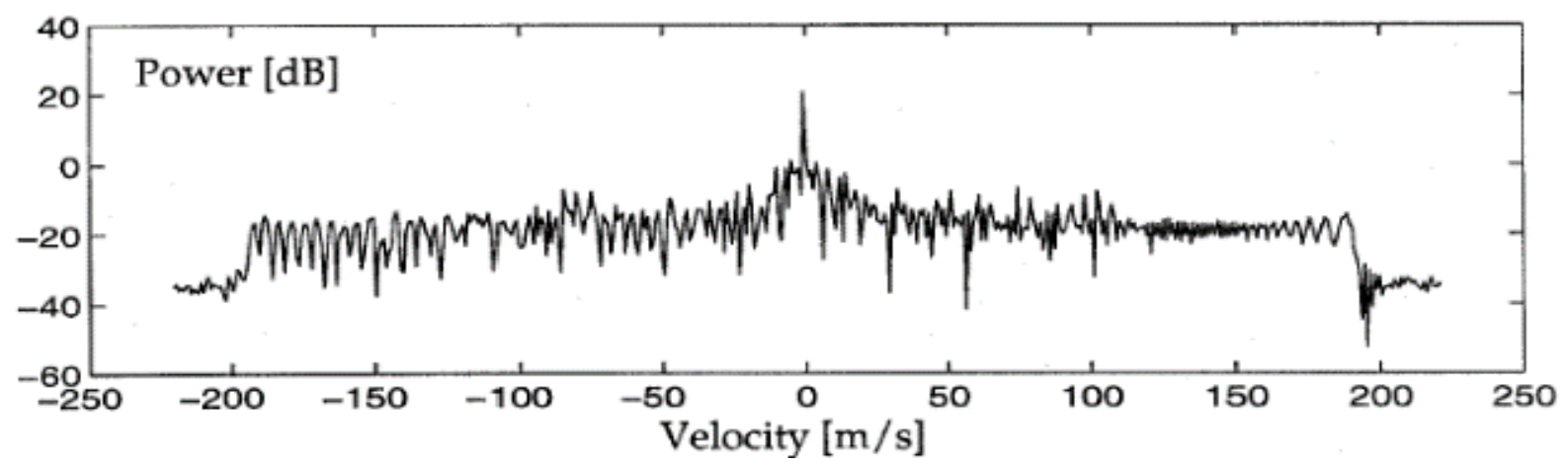

Fig.6. Helicopter Doppler signal in frequency domain

\subsection{Radar System}

Radar detects a target by sending radio frequency energy out from a transmitting antenna, and observing the returned echo. A pulsed radar transmits relatively short burst of electromagnetic energy, then the receiver is switched on to receive the echo. The time elapsed between the transmission of the pulse and the reception of the echo indicates the range of the target given by the following equation:

$\mathrm{R}=\frac{c \tau}{2}$

where, $\mathrm{R}$ is the range of the target, $c$ is the speed of light and is the $\tau$ pulse duration.

\subsection{Hovering Helicopter}

In tactical situations, attack helicopters normally hovering very close to ground especially 
during taking position just before the release point. Hence, the detection is likely to be clutter limited. Case study [6] demonstrates that the seeker of the sub munition is unable to detect a tank at the long range because the signal to clutter ratio is only $5 \mathrm{~dB}$, which is $10 \mathrm{~dB}$ less than required. In addition, the RCS of the helicopter is only about $10 \mathrm{~m}^{2}$ [7] which is much smaller than the RCS of a tank $\left(50 \mathrm{~m}^{2}\right)$. Furthermore, the backscatter coefficient at $94 \mathrm{GHz}$ is probably higher because most likely the attack helicopter hovers behind cover such as trees. If the target in the case study is replaced by a helicopter while the backscatter coefficient at 94 $\mathrm{GHz}$ replaced by $0.1 \mathrm{~m}^{2} / \mathrm{m}^{2}$ (trees), the beam foot print in one range cell is still the same but the now the footprint RCS increased to $158.8 \mathrm{~m}^{2} / \mathrm{m}^{2}$. Thus, the signal to clutter ratio is now given by

$\frac{S}{C}=\frac{10}{158.8}=0.063$

Since the signal to clutter ratio is too small, a better way to detect hovering is through the blade flash by making use of Doppler Effect.

\subsection{Doppler Effects}

The Doppler Effect is a phenomenon occurred when energy, transmitted as a wave motion, is incident on moving object where it undergoes a frequency shift upon reflection. The instantaneous incident and reflected frequencies when applied to a mixer device will produce a difference frequency which will vary with the speed of moving object. The Doppler angular frequency [8] is given by

$f_{d}=\frac{2}{\lambda} v_{r}=\frac{2}{c} v_{r} f_{o}$

where, $v_{r}$ is the radial velocity between radar and target, $\lambda$ is the wave length of transmitted frequency, fo is the transmitted frequency and $\mathrm{c}$ is speed of light. The radial velocity $v_{r}$, can also be written as $v_{r}=v \cos \theta$ where $\mathrm{v}$ is the relative speed between the target and the radar while $\theta$ is the angle between the target and the radar LOS. For example, if a fighter aircraft speed with the speed of $300 \mathrm{~m} / \mathrm{s}$ is flying towards a surveillance radar which is operating at 10 $\mathrm{GHz}$, the Doppler frequencies will vary according to the angle between the radar LOS and the aircraft. If the angle is 300 , the Doppler frequency will be

$f_{d}=\frac{2}{\lambda} v \cos \theta=\frac{2(300)}{0.03} v \cos 30=17.320 \mathrm{~Hz}$ 
The receiver of a pulse Doppler radar may be a homodyne or super heterodyne type. For a homodyne receiver, the function of the local oscillator is replaced by a leakage signal from the transmitter. Although this type of radar is simple, generally it is not very sensitive because of increased noise at lower frequencies due to flicker effect. The noise power due to flicker effect is proportional to $1 / \mathrm{f}^{\alpha}[8]$, where $\alpha$ is approximately unity. Hence, the performance of this type of receiver is less sensitive at lower frequencies at which the Doppler frequencies are normally found.

Super heterodyne receiver on the other hand is generally $30 \mathrm{~dB}$ [10] more sensitive than homodyne receiver because the flicker effect is minimized by using an intermediate frequency. However, this type of receiver is more complex because it requires local oscillator and IF amplifier. The existence in super heterodyne receiver of an intermediate frequency also allows the direction of a target to be identified whether it is approaching or receding since the sign of Doppler is preserved in a non-zero IF. It is achieved by using quadrature detector (I/Q channel processing) to determine the true sign of Doppler frequency. However, in the experiment that was conducted, the simple CW Doppler module did not have this capability. It was stated earlier that Doppler frequency varies according to the relative velocity between a radar and a target. However, helicopter rotor blade movement is quite different from other target such as a fixed wing aircraft or a tank moving on the ground. The blades are moving in a reciprocating manner relative to the radar LOS. Hence, the experiment that was conducted was to investigate whether the same phenomenon would occur as the angle between LOS of seeker head and the rotor plane varied.

\section{EXPERIMENTAL}

The aim of the experiment was to measure the pulse Doppler of hovering helicopter as the angle between the radar Line of Sight (LOS) and the rotor blades varied. Main equipment that were used during the experiment. A model helicopter was used to represent a real helicopter. The helicopter had a pair of main rotor blade and a pair of tail rotor blade. The length of the main rotor diameter was $1.54 \mathrm{~m}$ and the tail was $0.27 \mathrm{~m}$. Radar that was used during the experiment was continuous wave. The radar operating frequency was $10 \mathrm{GHz}$ and the Gunn 
diode oscillator capable of delivering $8 \mathrm{~mW}$ of power. A return signal $100 \mathrm{~dB}$ down on radiated power will be achieve from a man target of radar cross-section $1.0 \mathrm{~m} 2$ at a range of $15 \mathrm{~m}$. The radar had a homodyne receiver which was incapable of differentiating positive or negative Doppler frequencies.

All the Doppler frequencies will be folded on the positive side band. Since the size of rotor blades of model helicopter was about 10 times smaller than real helicopter, the RCS of the model's rotor blades should be much smaller. Therefore, an audio amplifier was used during the experiment to amplify Doppler signals before they were sent to an oscilloscope. An oscilloscope and a printer were used to capture the Doppler signals. The oscilloscope has a math function that transforms the signal received signals in time domain to frequency domain using FFT processing. The frequency resolution of the oscilloscope in FFT mode was $1 \mathrm{GHz}$. To vary the angle between the radar LOS and the rotor blades, an adjustable ramp was used. The ramp tilted the model helicopter at $0^{\circ}, 30^{\circ}$ and $60^{\circ}$.

\section{RESULTS AND DISCUSSION}

Fig. 7 shows the output of the oscilloscope when the LOS of the radar pointing straight towards the advancing and retreating blades (00 elevation). The highest Doppler frequency which represents the tip of the main rotor blades was $6.2 \mathrm{kHz}$. The relative amplitude at frequencies $5.8 \mathrm{kHz}$ to $6 \mathrm{kHz}$ was about $42 \mathrm{~dB}$.

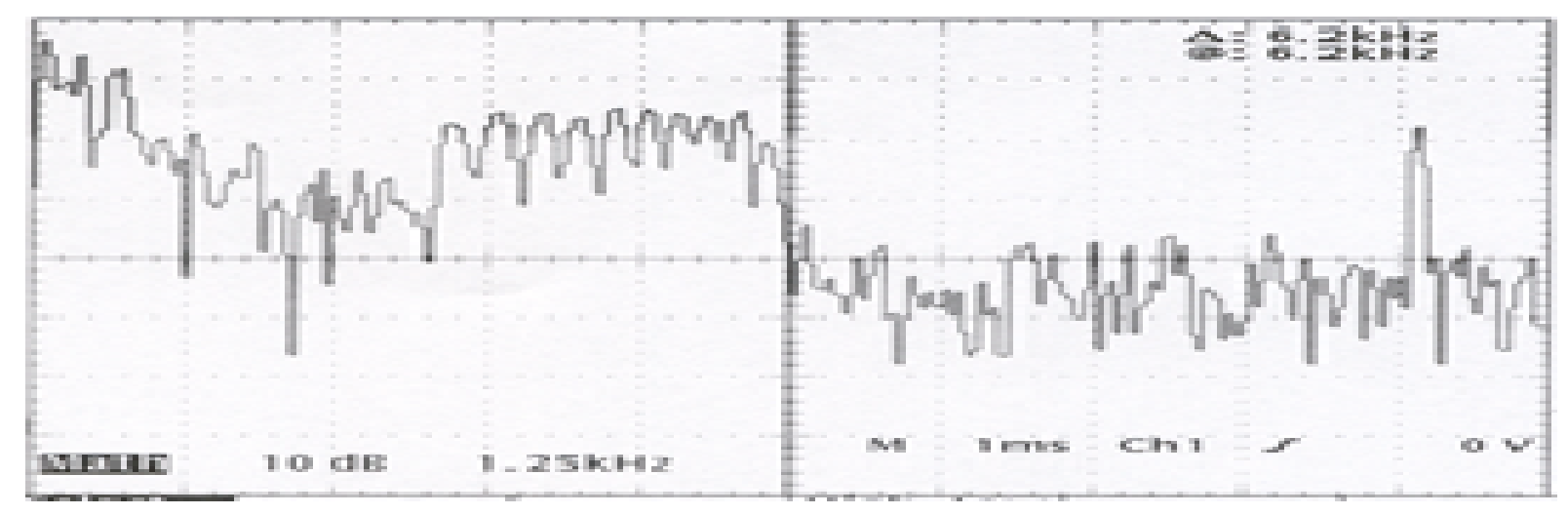

Fig.7. At $0^{0}$ angle and speed $1200 \mathrm{rpm}$

When the ramp was tilted at 300 angle, the main rotor tip Doppler frequency was about 5.0 $\mathrm{kHz}$ as shown in Fig. 8. At frequencies from $2 \mathrm{kHz}$ to $4 \mathrm{kHz}$, the relative amplitude was about $49 \mathrm{~dB}$. 


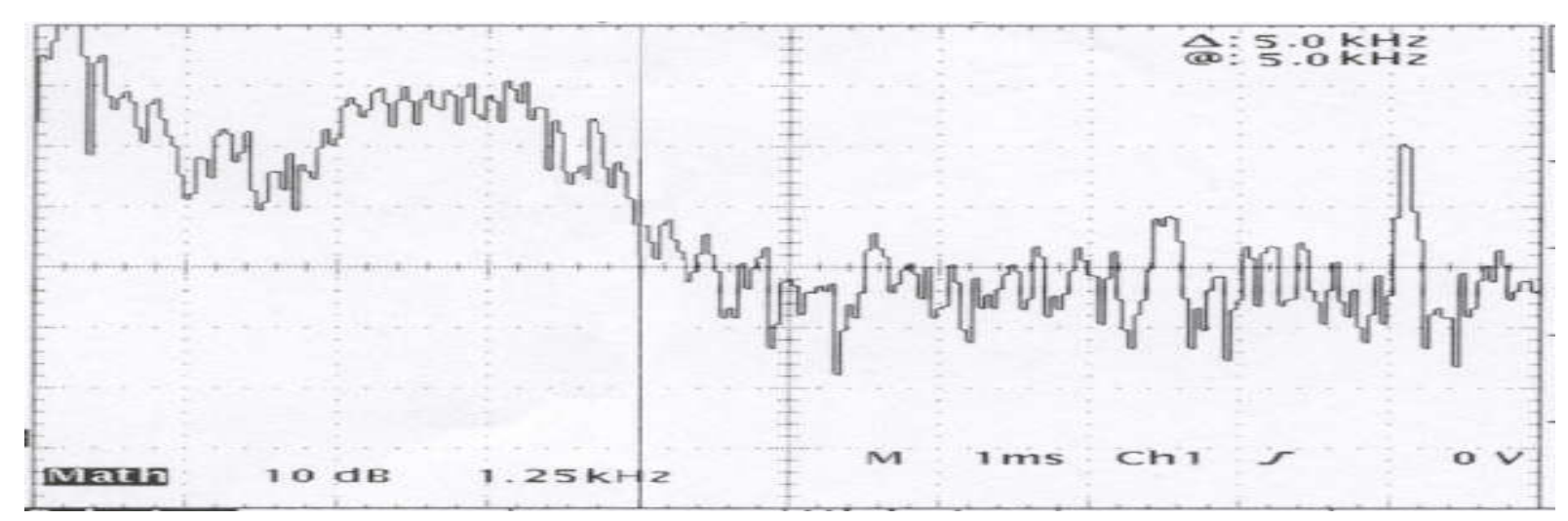

Fig.8. At $30^{\circ}$ angle and speed $1200 \mathrm{rpm}$

Fig. 9 show the output of the oscilloscope when the angle between LOS of the radar blades was at 600 . The utmost Doppler frequency was $3.15 \mathrm{kHz}$ and the relative amplitude for frequencies between $1.7 \mathrm{kHz}$ and $2.8 \mathrm{kHz}$ was about $50 \mathrm{~dB}$.

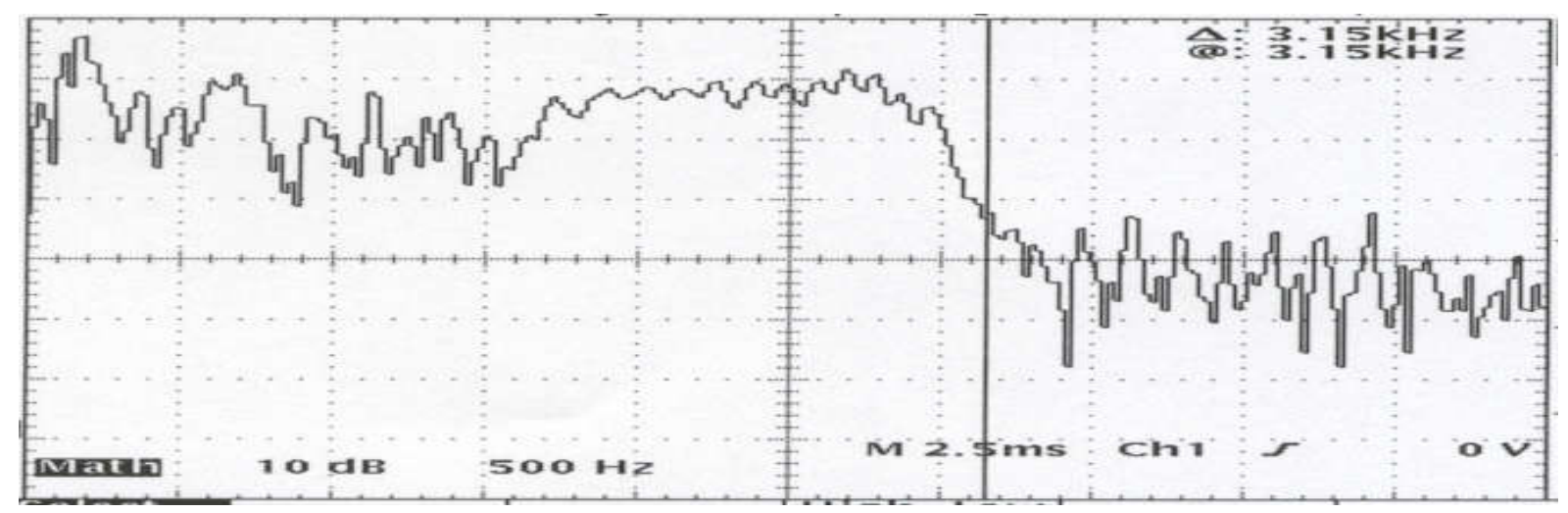

Fig.9. At $60^{\circ}$ angle and speed $1200 \mathrm{rpm}$

The experimental and theoretical Doppler frequencies is shown in Fig. 10.

\begin{tabular}{|c|c|c|c|c|}
\hline \multicolumn{5}{|c|}{$\begin{array}{l}\text { Main Rotor } \\
\text { Speed - } 1200 \text { rpm } \\
\text { Linear speed - } 96.77 \mathrm{~ms}^{-1}\end{array}$} \\
\hline \multicolumn{2}{|c|}{$\Theta($ Degree) } & $\mathrm{O}$ & 30 & 60 \\
\hline \multirow{3}{*}{$\begin{array}{l}\text { Doppler } \\
\text { Frequencies }\end{array}$} & Calculated Value (Hz) & 6451 & 5588 & 3226 \\
\hline & Experimental Value Hz) & 6200 & 5000 & 3150 \\
\hline & Differences & 712 & 986 & 306 \\
\hline \multicolumn{5}{|c|}{$\begin{array}{l}\text { Tail Rotor } \\
\text { Speed - } 7500 \text { rpm } \\
\text { Linear speed }-106 \mathrm{~ms}^{-1}\end{array}$} \\
\hline \multirow{3}{*}{$\begin{array}{l}\text { Doppler } \\
\text { Frequencies }\end{array}$} & Calculated Value (Hz) & 7067 & 6120 & 3534 \\
\hline & Experimental Value Hz) & Blocked & $\mathrm{N} / \mathrm{A}$ & $\mathrm{N} / \mathrm{A}$ \\
\hline & Differences & - & - & - \\
\hline
\end{tabular}

Fig.10. Measured and calculated values of Doppler frequencies

The Doppler spectrum of helicopter seeing at various angle is very different from other targets such as fixed wing aircraft and moving vehicles on the ground. There are few 
important points which can be made by analyzing Fig. 10 and Fig. 7 to Fig. 9. Fig. 8 indicates that the highest Doppler frequency reduces from $6.2 \mathrm{kHz}$ to $5.0 \mathrm{kHz}$ when the angle $\theta$ is increased to $30^{\circ}$. When the angle $\theta$ is increased to $60^{\circ}$, the highest Doppler frequency reduces to almost $50 \%$ as shown in Fig. 9. The decrease in Doppler frequencies confirms that the Doppler frequencies from the main rotor blades of a helicopter changes by the factor of $\cos \theta$, although the blades are moving in a reciprocating manner.

Since the velocity of the main rotor at the tip is very high, the bandwidth of the Doppler frequencies produced is very wide. When LOS of the radar pointing straight towards the plane of the main rotor blades $\left(\theta=0^{0}\right)$, the highest Doppler frequency is about $6.2 \mathrm{kHz}$. Nevertheless, when $\theta$ the Doppler frequencies is at $30^{\circ}$ is reduced to about $3.15 \mathrm{kHz}$. Although the amount is half, the bandwidth is still relatively wide and it is unlikely that the suppression of the main beam clutter will reject the entire Doppler spectrum from the helicopter.

Fig. 7 to Fig. 10 reveal that the strength of the Doppler signal increases as the angle between radar LOS and plane of the rotor blades increased. The strength level increases about $10 \%$ as the angle $\theta$ increases from $0^{0}$ to $60^{\circ}$. The strength of the Doppler signal should be increasing until the angle reaches $90^{\circ}$. At $90^{\circ}$, there should be no Doppler signal from the main rotor blades excepts from other components from the helicopter hub or from the tail rotor blades. This result signifies that Doppler frequencies from the rotor blades are almost available at any angle between radar LOS and the plane of the rotors.

Super heterodyne receiver which has $30 \mathrm{~dB}$ improvement in terms sensitivity may be able to detect Doppler frequencies from the tail rotor blades. The intermediate frequency in super heterodyne receiver also allows the sign of the Doppler shift to be identified. Hence, forward and reverse motion of the rotor blades can be used to discriminate helicopter from any other targets since both directions will always exist regardless the direction of the helicopter. If super heterodyne receiver is used, one might expect the Doppler spectrum of helicopter rotor blades as the angle $\theta$ varied to be as illustrated in Fig. 11. 


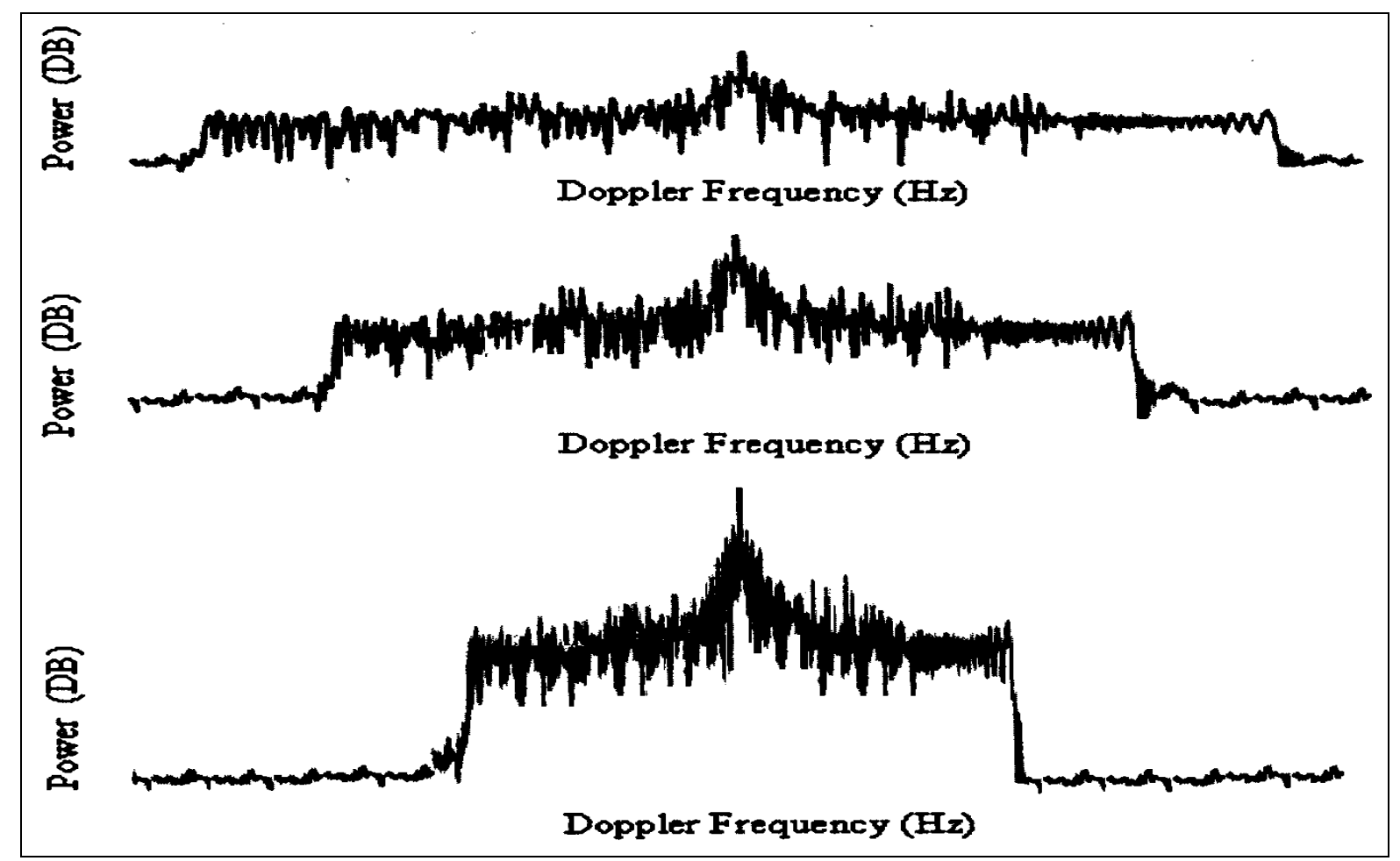

Fig.11. The pulse Doppler spectrum of a helicopter as the angle $\theta$ increases

Increase in the strength of the received signal also implies that the assumption made by [4] that rotor blade can be modeled as a stiff rod is not really correct at least from the point of view of an active seeker approaching from a high angle of elevation. Their assumption is valid if the radar is operating as a surveillance radar and in the experiment that they had conducted, the moving helicopter was detected at about $13 \mathrm{~km}$ and at height of about $200 \mathrm{~m}$. At that distance and height, the angle between the radar LOS between the helicopter main rotor blades was about $0.8^{0}$ which is very small. However, for a seeker's point, that rotor blades can be modeled as a flat plat because the results demonstrate that the signal strength varies at different angle. Furthermore, the main and the tail rotor blades of a helicopter are in fact almost a flat plate and they are constructed from carbon fiber material. Thus, the relationship between the RCS of the rotor blades and transmitter wavelength is be given by

$\sigma F P=\frac{4 \pi f^{2} A^{2}}{c^{2}}$

Above Equation (5) is valid for $A$ much greater than wavelength (Ibids, 75) where $\sigma F P$ is flat plate RCS, $f$ is the radar operating frequency, $A$ is the effective area of a flat plate and $c$ is the speed of light.

Flat plate is highly aspect dependent. When the angle between radar LOS and plane of the 
rotor is at $0^{0}$, the effective area for the main rotor blades is determined by the pitch angle. During the experiment, the pitch angle was about $9^{0}$. Thus, the effective area of the blades is much smaller than the actual dimension of the blades. When the angle between radar LOS and plane of the rotor was increased as illustrated in Fig. 8 and Fig. 9, more areas were illuminated because the radar was able to view the entire blades at almost all the time. Consequently, the RCS of the blades increased which explain the increased in the Doppler signal level.

For a real helicopter the velocity of the rotor blades is going to be much higher because the diameter is about 10 times longer. For example, the main rotor diameter of an Apache helicopter is $14.63 \mathrm{~m}$ and the tail rotor diameter is $2.97 \mathrm{~m}$. Based on Fig. 12, the speed at main rotor tip is about $221 \mathrm{~m} / \mathrm{s}$ and the speed at tail rotor tip is about $206 \mathrm{~m} / \mathrm{s}$. Thus, a FFT processor of a seeker head with proper filtering can easily distinguish the helicopter from other targets because it is very unlikely that other targets such as ground vehicles can move that fast. Even as the angle between the radar LOS and the plane of the rotor increases, good discrimination still can be achieved since the Doppler of other targets will be reduced at the same time.

Fig. 11 tabulates the expected Doppler frequencies from seeker heads operating at $10 \mathrm{GHz}, 35$ $\mathrm{GHz}$ and $94 \mathrm{GHz}$. A seeker operating $35 \mathrm{GHz}$ produces Doppler frequencies 3 times higher than a seeker operating $10 \mathrm{GHz}$, while $94 \mathrm{GHz}$ seeker generates Doppler frequencies 9 times higher than a seeker operating $10 \mathrm{GHz}$. Even when the angle between LOS of the radar and the plane of rotors is at $80^{\circ}$, the Doppler frequencies received by $94 \mathrm{GHz}$ seeker is almost twice higher than the radar operating at $10 \mathrm{GHz}$ with the angle between LOS of the radar and the plane of rotors is at $0^{0}$. Thus, missile trajectory is not limited if an active seeker head is used to engage a real hovering helicopter especially if the seeker is operating in milimetric wave $(\mathrm{mmW})$ region. 


\begin{tabular}{|c|c|c|c|c|c|c|}
\hline \multicolumn{7}{|l|}{$\begin{array}{l}\text { Main Rotor } \\
\text { Speed - } 288 \text { rpm }\end{array}$} \\
\hline \multicolumn{7}{|l|}{ Linear speed - 220ms-1 } \\
\hline$\theta$ (Degree) & 0 & 20 & 40 & 60 & 80 & 90 \\
\hline $\begin{array}{l}\text { Doppler frequencies }(\mathrm{Hz}) \text {, when } \\
\text { transmitter operating at } 10 \mathrm{GHz}\end{array}$ & 14667 & 13782 & 11236 & 7334 & 2546 & 0 \\
\hline $\begin{array}{l}\text { Doppler frequencies }(\mathrm{Hz}) \text {, when } \\
\text { transmitter operating at } 35 \mathrm{GHz}\end{array}$ & 51163 & 48077 & 39193 & 25582 & 8884 & 0 \\
\hline $\begin{array}{l}\text { Doppler frequencies }(\mathrm{Hz}) \text {, when } \\
\text { transmitter operating at } 94 \mathrm{GHz}\end{array}$ & 137500 & 129207 & 105331 & 68750 & 23877 & 0 \\
\hline \multicolumn{7}{|l|}{$\begin{array}{l}\text { Tail Rotor } \\
\text { Speed - } 1410 \mathrm{rpm} \\
\text { Linear speed - } 206 \mathrm{~ms}^{-1}\end{array}$} \\
\hline$\theta$ (Degree) & 0 & 20 & 40 & 60 & 80 & 90 \\
\hline $\begin{array}{l}\text { Doppler frequencies }(\mathrm{Hz}) \text {, when } \\
\text { transmitter operating at } 10 \mathrm{GHz}\end{array}$ & 13733 & 12905 & 10520 & 6866 & 2385 & 0 \\
\hline $\begin{array}{l}\text { Doppler frequencies }(\mathrm{Hz}) \text {, when } \\
\text { transmitter operating at } 35 \mathrm{GHz}\end{array}$ & 47907 & 45018 & 36699 & 23954 & 8319 & 0 \\
\hline $\begin{array}{l}\text { Doppler frequencies }(\mathrm{Hz}) \text {, when } \\
\text { transmitter operating at } 94 \mathrm{GHz}\end{array}$ & 126750 & 119106 & 97096 & 63375 & 22010 & 0 \\
\hline
\end{tabular}

Fig.12. Estimation of pulse Doppler frequencies of an Apache helicopter Detection range is also another important criterion in missile design. Normally, long detection distance is preferable since it will increase the no escape zone of the target. The detection range of a helicopter is generally determined by the seeker diameter, transmitter power and operating frequency. Generally, as frequency increases, antenna gain increases, total power decreases, minimum signal increases and losses increases. The net result is usually a reduced range. To demonstrate the influence of operating frequencies towards the detection range, case study [6] is used for the analysis. However, the tank is now replaced by helicopter main rotor blades which have the RCS about $0.5 \mathrm{~m}^{2}$ [2]. If the same fully active $\mathrm{mmW}$ seeker is used, the maximum detection range $(0 \mathrm{~dB} / \mathrm{km})$ is $2.025 \mathrm{~km}$. If the radar operating frequency is changed to $94 \mathrm{GHz}$, the Peak Power (PP) reduced to $20 \mathrm{~W}$, Smin increased to $10-11 \mathrm{~W}$ and the L increased to 6 , the range $(0 \mathrm{~dB} / \mathrm{km})$ is reduced to $1.518 \mathrm{~km}$.

However, the reduction in range one might ordinarily expect in going to the $\mathrm{mmW}$ band would be offset by increased in target RCS especially in the case of detecting helicopter main rotor blades since they can be assumed as flat plate as stated earlier. Equation (4) indicates that as the radar operating frequency increases, the flat plate RCS is increase by the factor of $f^{2}$. Furthermore, a real helicopter main rotor blades is about 10 times longer than the model 
helicopter. Hence, the RCS will be much bigger due to the term $A^{2}$ in Equation (5).

\section{CONCLUSION}

The experiment confirms that the Doppler frequencies do vary by the factor of $\cos \theta$, where $\theta$ is the angle between radar LOS and plane of the rotor blades. As the $\theta$ increase, the Doppler Frequencies reduced. However, for an active seeker head, the strength of the Doppler signal increases as the $\theta$ increased. It is due to fact that the rotor blade can be modeled as a flat plat where the effective RCS of the rotor blades increases. This signifies that Doppler frequency from the rotor blades is almost available at any angle between an active seeker head LOS and the plane of the rotors even when a helicopter is hovering. Super heterodyne receiver which has $30 \mathrm{~dB}$ improvement in terms sensitivity may be able to detect Doppler frequencies from tail rotor blades. The intermediate frequency in super heterodyne receiver also allows the sign of the Doppler shift to be identified. The analysis of the results concluded that mmW seeker head operating at either $35 \mathrm{GHz}$ or $94 \mathrm{GHz}$ is suitable be used as a missile seeker head to engage a hovering helicopter in terms of range and frequency resolution. A seeker head which employ super heterodyne receiver is an excellent choice because it enables the main and tail rotor to be detected. This type of receiver has the capability to confirm that it is about to engage a helicopter, and not something else nearby regardless whether a helicopter is flying or hovering.

\section{ACKNOWLEDGEMENTS}

This research work is supported by the (UPNM/2016/GPJP/4/ICT/1) research grant.

\section{REFERENCES}

[1] Burgos-García M, Pérez-Martínez F, Gismero M J. Radar signature of a helicopter illuminated by a long LFM signal. IEEE Transactions on Aerospace and Electronic Systems, 2009, 45(3):1104-1110

[2] Baczyk M K, Misiurewicz J, Gromek D. Analysis of recorded helicopter echo in a passive bistatic radar. In IEEE European Radar Conference, 2013, pp. 243-246 
[3] Clemente C, Soraghan J. Passive bistatic radar for helicopters classification: A feasibility study. In IEEE Radar Conference, 2012, pp. 946-949

[4] Misiurewicz J, Kulpa K, Czekala Z. Analysis of recorded helicopter echo. In IEEE Radar Systems, 1997, pp. 449-453

[5] Bullard B D, Dowdy P C. Pulse Doppler signature of a rotary-wing aircraft. IEEE Aerospace and Electronic Systems Magazine, 1991, 6(5):28-30

[6] Alabaster C M. Milimetric wave radar case study. RMCS Lecture Notes, 2001

[7] Misiurewicz J, Kulpa K, Czekala Z. Analysis of radar echo from a helicopter rotor hub. In IEEE 12th International Conference on Microwaves and Radar, 1998, pp. 866-870

[8] Merrill I. S. Introduction to radar systems. New Delhi: McGraw-Hill Education, 2015

\section{How to cite this article:}

Ahmad S, Ahmad KA.Doppler spectrum analysis of helicopter for an active seeker head. J. Fundam. Appl. Sci., 2017, 9(3S), 116-130. 